\title{
CONSTRUÇÃO DO PESQUISADOR NOS DISCURSOS DE MESTRANDOS(AS) EM EDUCAÇÃO EM CIÊNCIAS
}

\author{
Alessandra Rodrigues ${ }^{1}$
}

\begin{abstract}
RESUMO: Este estudo analisa discursos de discentes de um Programa de PósGraduação em Educação em Ciências de uma universidade federal brasileira sobre a posição-sujeito 'pesquisador'. Os discursos são oriundos de narrativas digitais de aprendizagem (NDA) produzidas no âmbito de uma disciplina obrigatória do Programa. Como atividade avaliativa da disciplina foi proposta a construção de NDA pelos(as) discentes para retratar e refletir sobre seus percursos curriculares e processos de aprendizagem ao longo do semestre letivo. Ainda que não fosse a proposição temática e reflexiva principal das narrativas, emergiram delas discursos indicativos do que os(as) discentes consideram como elementos constitutivos do sujeito-pesquisador em Educação: a) a centralidade da escrita e da autoria; b) o caráter processual da pesquisa e da formação do pesquisador; c) a possibilidade de articulação entre razão e emoção; d) a relação dialética entre pesquisa e prática pedagógica; e) o papel o pesquisador como agente transformador.
\end{abstract}

Palavras-chave: Educação em Ciências. Tecnologia educacional. Narrativas digitais. Formação de professores.

\section{CONSTRUCTION OF THE RESEARCHER IN SPEECHES OF MASTER'S STUDENTS OF SCIENCE EDUCATION}

ABSTRACT: This study analyzes the speech of students of a Postgraduate Program in Education in Sciences of a Brazilian federal university on the subject position 'researcher'. The discourses come from digital storytelling produced in a mandatory discipline of the Program. As an evaluation activity it was proposed the construction of digital storytelling by the students to retract and reflect on their curricular pathways and learning processes throughout the semester. Although it was not the main thematic and reflexive proposition of the narratives, discourses indicative of what the students consider as constituent elements of the subjectresearcher in Education emerged from them: a) the centrality of writing and

1 Doutora em Educação. Docente da Universidade Federal de Itajubá (Unifei). Itajubá-MG/Brasil Email:alessandrarodrigues@unifei.edu.br 
authorship; b) the procedural nature of the research and of the researcher's training; c) the possibility of articulation between reason and emotion; d) the dialectical relationship between research and pedagogical practice; e) the role of the researcher as a transformer agent.

Keywords: Education in Sciences. Educational technology. Digital storytelling. Teacher training.

\section{CONSTRUCCIÓN DEL INVESTIGADOR EN LOS DISCURSOS DE MESTRANDOS(AS) EN EDUCACIÓN EN CIENCIAS}

RESUMEN: Este estudio analiza discursos de discentes de un programa de Postgrado en Educación en Ciencias (PPGEC) de una universidad federal brasileña sobre la posición-sujeto 'investigador'. Los discursos proceden de narraciones digitales de aprendizaje (NDA) producidas en el marco de una disciplina obligatoria del PPGEC. Como actividad evaluativa de la disciplina se propuso la construcción de NDA por los discentes para retratar y reflexionar sobre sus recorridos curriculares y procesos de aprendizaje a lo largo del semestre lectivo. Aunque no fuera la proposición temática y reflexiva principal de las narrativas, surgieron de esas NDA discursos indicativos de lo que los discentes consideran como elementos constitutivos del sujeto-investigador en Educación: a) la centralidad de la escritura y de la autoría; b) el carácter procesal de la investigación y de la formación del investigador; c) la posibilidad de articulación entre razón y emoción; d) la relación dialéctica entre investigación y práctica pedagógica; e) el papel del investigador como agente transformador.

Palabras clave: Educación en Ciencias. Tecnología educativa. Narrativas digitales. Formación del profesorado.

\section{Introdução}

As narrativas digitais têm figurado em estudos recentes, nacionais e internacionais (ALMEIDA; VALENTE, 2017; CLARKE; ADAM, 2012; KOBAYASHI, 2012; RIBEIRO, 2014; ROBIN; McNEIL, 2012; RODRIGUES; ALMEIDA, 2017; RODRIGUES; GONÇALVES, 2014, dentre outros), como uma potente tecnologia educacional tanto na formação de professores, quanto nos mais diversos níveis de ensino. Além dos elementos clássicos do narrar, que materializam pela linguagem verbal (oral ou escrita) representações da experiência humana, a narrativa digital apresenta outras linguagens e semioses próprias das mídias digitais (músicas, imagens, animações, links etc.). Esses incrementos possibilitam a ampliação da composicionalidade 
hermenêutica (BRUNER, 1991) da narrativa e fomentam a construção dialógica do currículo por meio da prática reflexiva de construir, desconstruir e reconstruir a experiência de aprendizagem.

Assim,

[...] a elaboração de narrativas digitais permite desenvolver estudos sobre distintas experiências, contextos e conceitos por meio de um processo de representação do pensamento, reflexão, crítica, construção de conhecimento, atribuição de significados e negociação de sentidos entre os participantes (RODRIGUES; ALMEIDA; VALENTE, 2017, p. 79).

Nessa direção, este artigo tem como foco o olhar analítico para discursos emergentes de narrativas digitais de aprendizagem (NDA) produzidas por mestrandos(as) em Educação em Ciências, apresentando elementos indiciários das percepções destes sujeitos acerca do que é "ser pesquisador".

\section{Perspectivas Teóricas}

Na abordagem teórica adotada neste artigo, nossa constituição subjetiva se dá pela dispersão de múltiplos e diferentes 'eus' atravessados pelas posições-sujeito que ocupamos ao longo da vida e em diferentes contextos socioculturais de enunciação. Assim, a dispersão que nos constitui atravessa-nos pelas "[...] múltiplas e complexas identificações do sujeito que formam a identidade do eu" (ECKERT-HOFF, 2008, p. 63). Uma identidade vista, assim, como em permanente construção, como um processo em andamento e nunca como algo acabado e estático (MASCIA, 2011). Além disso, entendemos que a subjetividade, em sua constituição, está entrelaçada à produção de sentidos e de discursos sobre si, sobre o outro e sobre o mundo - de tal forma que a questão da subjetividade "[...] se caracteriza pela reflexividade, que é a nossa capacidade de receber sentido, questionar o sentido e criar um novo sentido [...] É saber que sabemos, e interrogar-se sobre tal saber, é colocar a si mesmo como objeto por posição e não por natureza" (EWALD; SOARES, 2007, p. 25).

Nessa direção, compreendemos que sujeito e discurso constituem-se em movimentos de memória, enunciação e interpretação, e que "Não há sujeito, nem sentido, que não seja 
dividido, não há forma de estar no discurso sem constituir-se em uma posição-sujeito discursiva que, por sua vez, é a projeção da ideologia no dizer" (ORLANDI, 2012, p. 55). Dessa forma, no que concerne à constituição subjetiva da posição-sujeito 'pesquisador', as questões ideológicas, éticas, políticas e científicas se fazem presentes e atravessam os discursos num movimento dialético em que sujeito e discurso constituem-se mutuamente e atuam no mundo em diálogo com o outro. "Em uma perspectiva mais ampliada, é possível afirmar também que a busca pelo conhecimento em Ciências Humanas promove sempre o encontro entre os diferentes eus personificados nas relações entre as figuras do pesquisador e dos sujeitos de pesquisa" (RODRIGUES, 2017, p. 65).

Daí também a necessidade de compreendermos os entrelaçamentos discursivos e intersubjetivos dessa posição-sujeito percebendo, com Freire (2001), que epistemologia e ontologia integram um mesmo movimento histórico, uma vez que "O conhecimento se constitui nas relações homem-mundo, relações de transformação, e se aperfeiçoa na problematização crítica destas relações" (FREIRE, 2001, p. 36). Assim, considerando que o homem é um sujeito social, histórico-cultural e simbólico e que a forma-sujeito-histórica na contemporaneidade é a forma capitalista, é no processo de individualização dos sujeitos pelas instituições que a educação pode incidir e "[...] é também aí que podemos pensar tanto a reprodução como a resistência, a ruptura e os movimentos (dos sujeitos, dos sentidos, da sociedade, da história etc.)" (ORLANDI, 2012, p. 154).

Tendo em vista esses pressupostos teóricos, voltamo-nos ao papel da escrita de si nas narrativas digitais pelas quais acessamos, neste estudo, os discursos dos sujeitos sobre a posição-sujeito 'pesquisador'. Entendemos as NDA a partir da definição de Rodrigues (2017, p. 128).

\footnotetext{
Narrativas digitais de aprendizagem são aquelas narrativas cujo enfoque temático centra-se no processo formativo dos sujeitos narradores (ainda que tenha diferentes recortes contextuais e temporais), são construídas com uso de tecnologias digitais de informação e comunicação, utilizam recursos multimodais de linguagem em sua constituição e se apresentam por meio de suportes multi ou hipermidiáticos.
} 
Ao produzir uma narrativa digital de aprendizagem, as identificações, os sentidos e as significações dos sujeitos saem do mundo das ideias e ganham corpo materializando-se na escritura de si. Um escritura que também extrapola os limites da escrita tradicional e permite a representação do pensamento por meio de diferentes linguagens e múltiplas semioses. Como refere Santaella (2007), a possibilidade de produção de conteúdos em áudio, animações, vídeos etc., aberta pela internet e por novas interfaces de programação, tem impactos diretos não somente na escrita, mas também no que é a escritura. Nas mídias digitais, a escritura existe dentro de outras condições de textualidade (multi e hipermidiáticas).

Assim, entendemos que as narrativas digitais aliam nossa forma clássica de registrar histórias e memórias, revivê-las e (re)significá-las a elementos próprios das Tecnologias Digitais de Informação e Comunicação (TDIC), permitindo a construção de novos sentidos e subjetividades. "Pelo narrado, recuperamos o vivido, o pensado, o imaginado, o sonhado, o não-dito; que, ao serem acessados pelo corpo da escrita, revivem e ganham outros/novos sentidos modificando também o sujeito que escreve" (RODRIGUES, 2017, p. 111). Essa ideia encontra sustentação em Foucault (1992, p. 143-144), quando o autor afirma que:

A escrita transforma a coisa vista e ouvida "em forças e em sangue". Ela transforma-se, no próprio escritor, num princípio de acção racional. Em contrapartida, porém, o escritor constitui a sua própria identidade mediante essa recolecção das coisas ditas. [...] Pelo jogo das leituras escolhidas e da escrita assimiladora, deve tornar-se possível formar para si próprio uma identidade.

Nessa direção, a narrativa digital de aprendizagem, bem como os saberes, conhecimentos e ideias que ela corporifica, pode ser compreendida "[...] como um exercício de razão na medida em que, pelo escrito, o sujeito recolhe, organiza a experiência e debruçase sobre ela refletindo e assimilando-a assim como se preparando para o devir" (RODRIGUES, 2017, p. 111). Desde essa perspectiva, os discursos de sujeitos mestrandos(as) acerca da posição-sujeito 'pesquisador' poderiam trazer tanto memórias quanto inspirações e perspectivas constitutivas de suas subjetividades como pesquisadores(as) em formação. 


\section{Aspectos metodológicos}

As NDA a partir das quais foi constituído o corpus de análise deste estudo foram produzidas como atividade curricular de uma disciplina obrigatória de um Programa de PósGraduação em Educação em Ciências de uma universidade pública brasileira. A disciplina foi ministrada pela autora deste artigo e teve, no primeiro semestre de 2018 , vinte e cinco estudantes matriculados - sendo a maior parte (23) constituída por ingressantes no Programa. A ementa da disciplina está assim redigida.

Tendo como foco os modos de construção do pensamento científico na Educação em Ciências, a dinâmica da disciplina constitui-se de estudos e apresentações de trabalhos de pesquisa concluídos ou em andamento, realizados por pesquisadores da área. Promovendo a discussão teórico-metodológica concernente às pesquisas em educação em Ciências, a disciplina oportunizará também o exercício diversificado de confecção de trabalhos acadêmicos para o desenvolvimento de competências linguísticas e de elaboração textual científico-acadêmicas importantes para a formação do pesquisador (PPG, 2016, online).

Pelo conteúdo da ementa, a disciplina tem dois grandes focos de trabalho: os estudos desenvolvidos no campo da Educação em Ciências e as práticas de escrita acadêmicocientífica. Nesse sentido, os objetivos propostos para a oferta da disciplina no primeiro semestre de 2018 foram assim descritos no Plano de Ensino.

A disciplina tem por objetivos levar o(a) discente a:

- Aproximar-se da área de pesquisa em Educação em Ciências;

-Refletir sobre diferentes possibilidades teórico-metodológicas que embasam os estudos da área;

- Conhecer e exercitar a leitura e a produção de gêneros textuais acadêmico-científicos;

- Refletir sobre o próprio processo de aprendizagem por meio de elaboração processual de narrativa digital.

A disciplina tem carga horária de 30 horas semestrais, ao logo das quais foram realizados oito seminários proferidos por docentes do Programa e por um docente da Universidade de Lisboa. Também foram realizados sete encontros voltados ao trabalho com 
gêneros textuais do universo acadêmico e dois encontros dedicados à apresentação das narrativas digitais (versões parciais e versões finais). As narrativas digitais, propostas já no primeiro encontro da disciplina como atividade avaliativa do semestre, deveriam apresentar, de forma crítico-reflexiva, o percurso curricular e formativo dos(as) discentes ao longo da disciplina. Essa proposição encontra aporte em estudos como os de Almeida e Valente (2012, 2014), Rodrigues (2017) e Rodrigues, Almeida e Valente (2017) e entendendo que essas narrativas se configuram "[...] como um espaço aberto para a vivência de processos de reconhecimento e autorreconhecimento dos sujeitos como sujeitos de conhecimentos e de experiências" (RODRIGUES, 2017, p. 233).

O corpus de análise deste estudo é composto por recortes discursivos das narrativas digitais finais de discentes nos quais percebemos a emergência de discursos acerca da posição-sujeito 'pesquisador' - ainda que a temática geral das narrativas não fosse essa. Assim, salientamos o fato de que os discursos sobre a constituição do pesquisador que emergiram das NDA foram, de certa forma, espontâneos no que se refere a sua inclusão das narrativas, mas refletem, em grande medida, os processos reflexivos e constitutivos dos(as) mestrandos(as) acerca de suas aspirações, inspirações e constituição como pesquisadores em formação. Coincidentemente, apenas mestrandas aparecem no recorte deste estudo. Por essa razão, daqui em diante, não utilizaremos mais a duplicidade de gênero representada pelo uso de "(as)" ao final de algumas palavras masculinas.

O corpus foi analisado pela perspectiva da Análise de Discurso de linha francesa buscando colocar o dito em relação ao não-dito (ORLANDI, 2013) e tendo como pressuposto a ideia de que a linguagem não é transparente, mas opaca e sempre atravessada pela ideologia, pela memória discursiva e pelas condições de produção do discurso. Assim, não pretendemos esgotar os sentidos nem tampouco fechar suas significações a partir de nossas análises, uma vez que compreendemos que "[...] a construção de sentido de todo discurso é, por definição, inacabável" (AMORIM, 2004, p. 19).

Cabe informar ainda que a utilização dos recortes discursivos para este estudo foi devidamente autorizada pelas mestrandas e suas identidades estão preservadas. Os nomes 
pelos quais é feita a identificação de autoria nos recortes discursivos analisados foram escolhidos pelas próprias autoras das narrativas digitais.

\section{Análises e Discussão}

Neste tópico, apresentamos os recortes discursivos das NDA e os analisamos a partir da construção de sentidos possíveis sobre a posição-sujeito 'pesquisador' . O primeiro sentido que emerge nos discursos dos sujeitos se refere à escrita como elemento central do trabalho e da constituição do pesquisador. Nos recortes discursivos, a seguir, cinco mestrandas retomam em seus discursos os sentidos do escrever na/para a pesquisa.

"É por meio da escrita que a pesquisa ganha estrutura. A imaginação criativa permeará todo o trabalho do pesquisador." (Flávia)

"[...] compreendi a indossociação entre a escrita e a pesquisa científica, reconheci o aprimoramento da escrita no seu constante exercício e processo de construção e percebi que enquanto escrevemos, pensamos!" (Bárbara)

"[...] levando a refletir sobre a importância do exercício da escrita na pesquisa e na vida do pesquisador. Afinal, eu estou me dispondo a ser uma pesquisadora, então deveria exercitar não somente a leitura, mas também a escrita." (Elisa)

Nesses três primeiros recortes discursivos, as mestrandas recuperam, pelo processo parafrástico (ORLANDI, 2013), sentidos produzidos durante as aulas e por discursos da docente reincidentemente presentes nos encontros da disciplina. Os sentidos recuperados e ressignificados pelas discentes sobre a relação escrita/pesquisa ao mesmo tempo em que estabilizam sentidos produzidos no mestrado, provocam deslocamentos e rupturas - pelo processo polissêmico (ORLANDI, 2013) -, uma vez que trazem ideias pouco disseminadas na formação escolar e também em nível de graduação: a) a de que a escrita científica também exige imaginação criativa; b) a de que existe um processo de aprimoramento da escrita; c) a de que a escrita nos ajuda a pensar; d) a de que a escrita é 'exercício' constante para o pesquisador.

Ao sedimentarem esses 'novos' sentidos advindos da disciplina e ao mesmo tempo 
romperem com processos de significação antes presentes em seus contextos discursos como graduandas, as mestrandas indicam um movimento formativo de apropriação de ideias que de certa forma desconstroem memórias discursivas frequentemente associadas à escrita científica, como a de que o texto deve ficar pronto em sua primeira versão ou a de que o pesquisador é, a priori, alguém que tem o dom da escritura. Assim, os recortes discursivos indicam que

Se toda vez que falamos, ao tomar a palavra, produzimos uma mexida na rede de filiação dos sentidos, no entanto, falamos palavras já ditas. $E$ é nesse jogo entre paráfrase e polissemia, entre o mesmo e o diferente, entre o já-dito e o a se dizer que os sujeitos e os sentidos se movimentam, fazem seus percursos, (se) significam (ORLANDI, 2013, p. 36).

A autoria, elemento também presente nas interlocuções realizadas na disciplina e relacionada à escrita, aparece no recorte discursivo de Mariana associada à construção da posição-sujeito 'pesquisador'

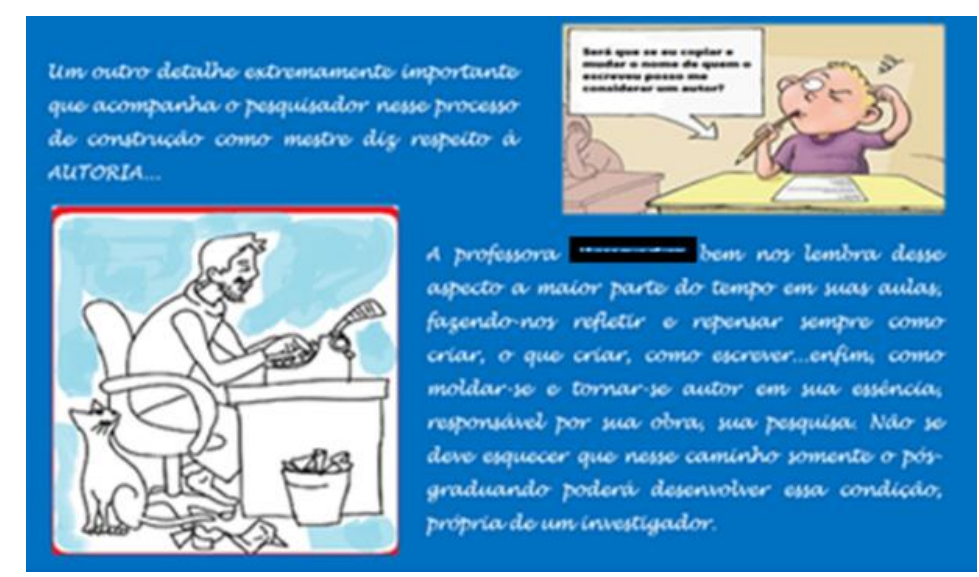

Recorte discursivo da narrativa de Mariana Fonte: Dados de pesquisa

Nesse recorte, Mariana associa a autoria tanto à escrita (pela imagem no canto inferior esquerdo) quanto a uma condição que é própria do investigador e que pode ser desenvolvida, ou seja, não está dada a priori. Mais uma vez, paráfrase e polissemia se articulam para a estabilização de alguns sentidos e a produção de outros. A imagem no canto superior direito da tela também indica o processo reflexivo e dialético da mestranda na construção do que ela 
considera como sendo a posição-sujeito 'pesquisador'. O personagem pensativo se pergunta: "Será que se eu copiar e mudar o nome de quem escreveu, posso me considerar um autor?". Ao trazer para o seu discurso a imagem e a pergunta associadas, a mestranda leva o leitor a indagar-se e a produzir sentidos e respostas possíveis desde a relação estabelecida com o que Mariana afirma nos demais textos da tela, pelos quais explicita sua noção de autoria.

A desestabilização da memória discursiva sobre o que é o texto acadêmico em sua forma aparece no discurso de Moreninha, quando a mestranda escreve.

"[...] Pensei: Que mulher é essa, meu Deus? Como assim ela fugiu da rigidez acadêmica? [...] passei por um processo de (re)conhecimento da minha visão como pesquisadora, desde as terminologias até a forma fixa que via a escrita acadêmica".

A surpresa da mestranda com a desestabilização de uma memória discursiva atravessada pela ideologia positivista acerca de como deve ser o discurso da ciência pode ser percebida nas duas primeiras perguntas, cujos sentidos remetem às regras de escrita acadêmica enquanto uma espécie de prisão da qual não é possível escapar.

As ideias do pesquisador como um 'caçador de tesouros' e de pesquisa como 'quebracabeça' são indiciárias de um discurso parafrástico sobre o caráter processual da pesquisa e percebidas nos discursos de algumas discentes:

"[...] Porque eu queria fazer essa articulação na minha pesquisa. Mas nas palavras da professora isso seria uma 'caça ao tesouro'. Não me importo em caçar esse tesouro, pois é ele que me fascina, é ele que me atrai, esse tesouro pouco estudado e cintilante. [...] É isso que quero buscar". (Alice)

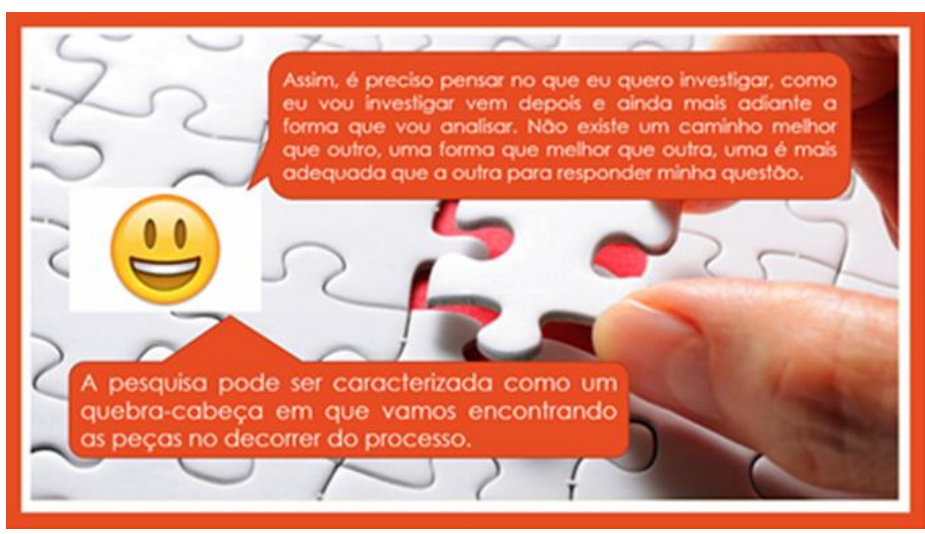

Argumentos Pró-Educação, Pouso Alegre, v. 4, n. 10, p. 709-730, jan.- abr., 2019 ISSN: 2448-2803 http://dx.doi.org/ 10.24280/ape.v4i10.458 
Desses dois recortes, é possível depreender um sentido comum: o de que o trabalho do pesquisador não se estrutura somente a partir de certezas, mas se faz por 'pistas' (como numa caça ao tesouro) e pela junção de peças (como no quebra-cabeças) tendo apenas em projeção o tesouro ou a imagem final do quebra-cabeça. Esses discursos estão atravessados por formações ideológicas (BRANDÃO, 2012) próprias do paradigma das pesquisas qualitativas.

Também recuperam essas formações ideológicas os discursos Bia e Moreninha.

"A importância do trabalho artesanal da pesquisa [...] Lagarta que não sai do casulo, não vira borboleta." (Bia)

"Espera! Aí que está parte do segredo acadêmico - tudo é PROCESSUAL! Nada é pronto e acabado. Nada sai como esperado, aliás, esse é o triste ou o feliz risco que corremos, rsrs. BEM-VINDOS À PESQUISA ACADÊMICA!" (Moreninha)

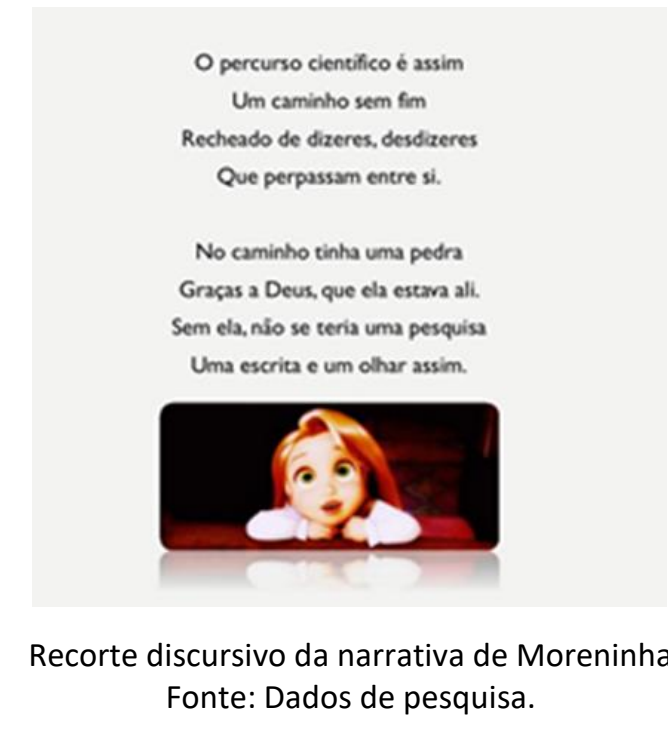

A referência metafórica à lagarta e à borboleta, feita por Bia, produz sentidos em torno do trabalho e do tempo necessários à pesquisa. Para se tornar 'borboleta', é preciso que o pesquisador de dedique à produção do casulo, ao isolamento e finalmente à exposição. Se recuperarmos as ideias de beleza, leveza e liberdade associadas à borboleta e as ideias 
contrárias associadas ao casulo, podemos depreender da metáfora a noção de metamorfose. Em um exercício de associação discursiva, o pesquisador seria aquele que passa por essa metamorfose e, como a borboleta, pode ser admirado em seu esplendor.

Assim, remetemo-nos a formações ideológicas historicamente construídas acerca dessa posição-sujeito e segundo as quais o pesquisador é alguém especial, diferenciado. Ao mesmo tempo, o discurso de Bia é polissêmico e rompe com essa concepção ao associar o trabalho de pesquisa à artesania - algo que pode ser aprendido e realizado, que implica em “[...] experimentação, investigação, espaços produtivos e produto final, pelos quais o artesão transita para ter um resultado adequado, o que inclui, ainda, a inventividade e a necessidade de métodos apropriados" (DICIONÁRIO INFORMAL, online) - o que, de certa forma, "desmistifica" a figura do pesquisador.

No segundo recorte discursivo, as letras maiúsculas na palavra "processual" e na frase "bem-vindos à pesquisa acadêmica" associadas a "segredo acadêmico" promovem o deslizamento de sentidos no discurso de Moreninha. Ao anunciar a descoberta do 'segredo' e em seguida dar as boas vindas, a mestranda reproduz, de alguma maneira, uma memória discursiva pela qual o mundo da pesquisa é para poucos 'iluminados' que conhecem o segredo do universo do conhecimento científico, e não para os que dominam somente o conhecimento comum.

Na tela do terceiro recorte discursivo, Moreninha associa a pesquisa a um caminho sem fim no qual encontramos pedras, mas coloca estes obstáculos como bem-vindos e é grata por eles. Os 'dizeres e desdizeres' também podem produzir o mesmo sentido das pedras e remetem ao movimento da pesquisa como percurso entrecortado por percalços. Nesse recorte, a mestranda recupera parafrasticamente discursos de vários docentes que ministraram seminários ao longo da disciplina e se insere nessa formação discursiva. $O$ sentido de "pedra" se constitui, assim, em associação com desafio e não com obstáculo num processo polissêmico pelo qual o sentido 'dessa pedra' difere de sentidos mais estabilizados discursivamente para a palavra, como na frase: "uma pedra no sapato". Nessa direção, vemos o funcionamento discursivo pelo qual, como aponta Orlandi (2013, p. 44), "Palavras iguais 
podem significar diferentemente porque se inscrevem em formações discursivas diferentes".

Os recortes apresentados a seguir têm em comum o processo de (re)significação pela recuperação parafrástica do discurso de possibilidade de associação entre razão e emoção na constituição do sujeito-pesquisador. Pela recuperação da memória discursiva dos encontros e seminários apresentados na disciplina, as mestrandas autorizam-se, em seus discursos, a associar a posição-sujeito 'pesquisador' a ideias de subjetividade, surpresa, humanidade e comunhão de vozes

"Achei incrivel vocês trazerem a vivência e as inquietudes que Ihes perpassaram até aqui. [...] a não desvinculação entre o pesquisador e a sua subjetividade [...] Não adianta tentar se livrar de toda subjetividade possível, quando se é pesquisador realmente, levamos o olhar investigativo para a realidade que nos cerca e vice-versa". (Moreninha)

"[...] podemos desconstruir a ideia de pesquisa fria, que apenas coleta dados e os analisa. Sim, ela pode nos tocar, nos modificar, pode nos levar por rumos que não planejamos, uma viagem que pode se tornar reveladora, surpreendente". (Maria)

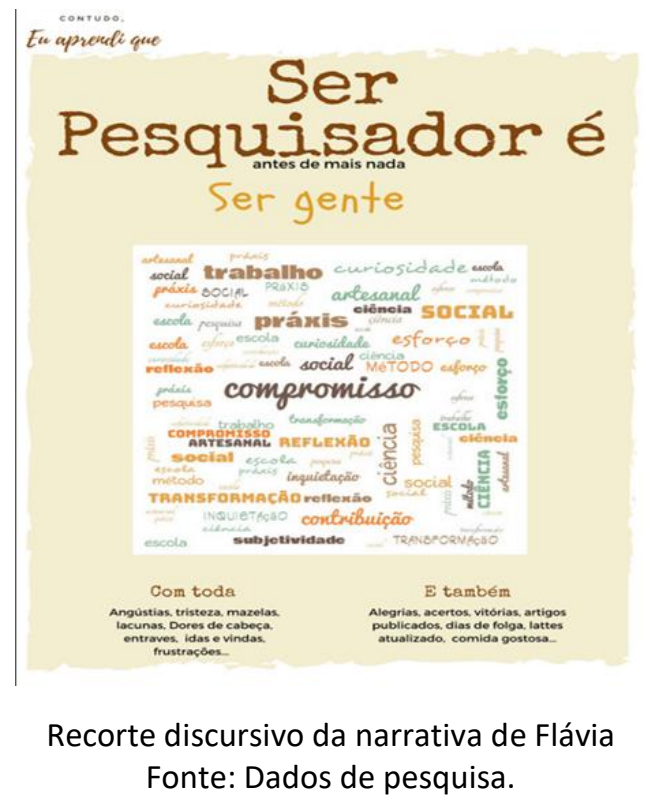

A minha pesquisa me constrói como ser humano todos os dias. [...] Então, hoje, eu me faço como pesquisadora de ciências humanas. (Manuela - transcrito)

"O que eu quero, na minha pesquisa, senão a comunhão de ideias entre as vozes 
caladas? Inclusive a minha". (Violeta)

Ao mesmo tempo em que recuperam memórias discursivas e se inserem em formações que estabilizam os sentidos produzidos no mestrado, os discursos contestam formações ideológicas de caráter mais positivista acerca de neutralidade da ciência, ainda que isto produza sentidos pelo não-dito do discurso. Assim, mesmo o que o sujeito "[...] não diz (e muitas vezes ele desconhece) significa em suas palavras" (ORLANDI, 2013, p. 34).

O discurso sobre a relação dialética entre pesquisa e prática pedagógica, presente na disciplina, é recuperado e (re)significado nos recortes seguintes, quando as mestrandas associam o pesquisador a uma posição-sujeito em constante construção/transformação e enquanto agente de formação e transformação da realidade.

"Talvez eu tenha um olhar muito romantizado do mundo. Tavez seja utopia. Mas a utopia é um caminho, é para onde quero ir. O meu 'ser pesquisador' procura um mundo melhor e quero ser parte da mudança. [...] É possível ser professor-pesquisador mesmo no Ensino Básico: olhar para sua própria prática, questionar, refletir, mudar". (Flávia)

"E fui construindo em mim, com cada experiência compartilhada, o desejo de trilhar pela pesquisa, de fazer a diferença, de contribuir com a ciência, de aceitar o desafio, de fazer parte da mudança". (Amanda)

"[...] pontos-chave no que se refere à compreensão do papel de um pesquisador, como sua ação pode transformar o cenário educacional e estimular o aluno a estudar ciências". (Mariana)

As palavras "mudança" e "transformar", presentes nos três recortes, carregam um sentido não-dito que remete à discordância das mestrandas em relação às atuais condições da educação no país. Querer fazer parte da mudança produz também o sentido de: "as coisas não estão boas como estão". Nesse movimento, as mestrandas tanto parafraseiam sentidos já estabilizados sobre a educação básica brasileira como produzem novos sentidos, pela polissemia, ao incluírem o pesquisador como elemento agente de mudanças e não somente como alguém distante da realidade social e isolado em contextos de certa forma privilegiados - como as universidades. 
Esse novo sentido produzido também pode ser percebido nos recortes discursivos das narrativas digitais de aprendizagem de Raquel, Elisa e RM, apresentados a seguir.

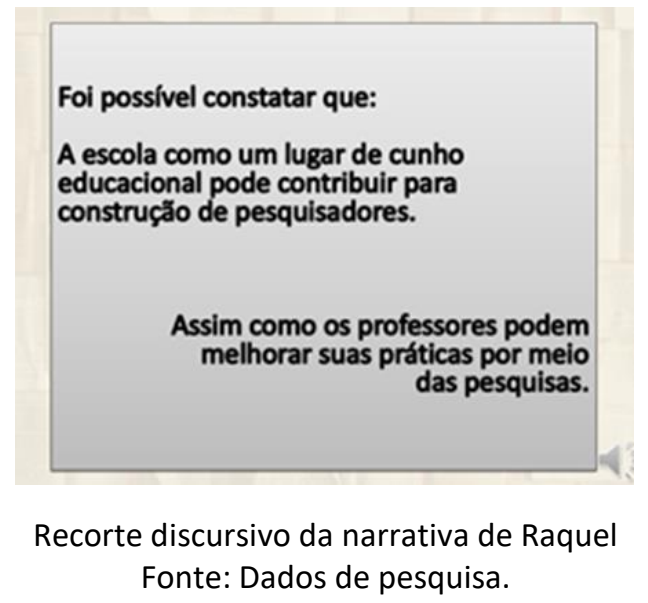

"[...] fazemos pesquisa também para gerar efeitos. Como futura pesquisadora é essencial que eu dê retorno de minhas pesquisas, não somente para saber a realidade local, mas para que minhas pesquisas tenham frutos e provoquem reflexões!" (Elisa)

"O percurso e a vida acadêmica exigem produção intelectual progressivamente mais aprofundada e abrangente e isso se dá pela escrita científica que não repousa apenas na descoberta do inusitado, mas também na articulação e rearticulação do tido com o sabido, ao abrir novas possibilidades interpretativas ou perspectivas propositivas". (RM)

Os recortes anteriores se inserem em uma formação ideológica - própria do Programa de Pós-Graduação em que estão inseridas as mestrandas - segundo a qual a função-sujeito 'pesquisador' na área de Educação não pode estar dissociada da função-sujeito 'professor'. Ainda que não o façam conscientemente, as mestrandas contribuem, pela relação discursiva memória/esquecimento (ORLANDI, 2012, 2013), para a estabilização de sentidos propostos pelo próprio Programa e manifestos, dentre outros espaços, em seu website: “[...] o programa está comprometido com a construção de uma escola pública de qualidade e com a promoção de uma sociedade mais justa e sustentável". Considerando as condições de produção do discurso no contexto da disciplina do mestrado, podemos dizer que as mestrandas parafraseiam tanto discursos escritos institucionais do Programa quanto orais (dos docentes 
que passaram pela disciplina) num gesto de interpretação próprio do dizer, já que, como refere Orlandi (2012, p. 171), "Para que nossas palavras façam sentido é preciso que elas já signifiquem, que se produzam em uma memória discursiva, que possam ser interpretadas. Falamos com palavras que (já) fazem sentido".

Talvez, e em parte decorrente da relação dialética entre pesquisa e educação, entre as posições-sujeito 'pesquisador' e 'professor', os discursos de Raquel e Gisa acrescentam mais um elemento, pela via discursiva, à constituição do pesquisador: a influência das pesquisas realizadas sobre a constituição subjetiva do pesquisador.

"A pesquisa também pode mudar o pesquisador". (Raquel)

"A pesquisa como prática reflexiva, crítica e transformadora da realidade social com certeza não deixa marcas somente nos sujeitos estudados, mas também em quem os estuda e propõe mudanças". (Gisa)

Os sentidos produzidos pelos discursos de Raquel e Gisa, de certa forma, desestabilizam sentidos mais tradicionais sobre a posição-sujeito 'pesquisador' como alguém já pronto, formado; como um sujeito alheio ao objeto pesquisado. Nessa direção, pelo processo polissêmico, produzem diferentes sentidos para essa posição-sujeito, como alguém em permanente formação/transformação, como um sujeito que se relaciona com o objeto estudado. Esses discursos contestam, pelo não-dito, os estereótipos associados à posição e à figura social do pesquisador - como também o fazem Amanda e Maria, nos recortes discursivos a seguir:

"Tinha me preparado para as respostas e não para as perguntas. Li textos, fiz pesquisas, anotei dados importantes... Mas ao ouvir se estaríamos preparados para fazermos perguntas, um sinal de alerta acendeu em mim. Não! Eu não estaria preparada para isto!" (Amanda)

O não-dito do discurso de Amanda se revela pela relação de sentidos entre "perguntas e respostas". Ao se preparar para ser pesquisadora, a mestranda entende como característica desta função "dar respostas". Entretanto, assusta-se ao perceber que o pesquisador é um "perguntador". Os sentidos associados à 'resposta' são da ordem do saber, do conhecer, do 
entender; enquanto os sentidos para 'pergunta' são da ordem inversa (do não saber, não conhecer, não entender). Assim, o discurso de Amanda remete ao atravessamento do discurso pela ideologia e às formações ideológicas que constroem os sujeitos sem suas diferentes posições.

O recorte discursivo da narrativa de Maria traz outro viés que desestabiliza sentidos sedimentados pelos discursos mais tradicionais sobre a ciência:

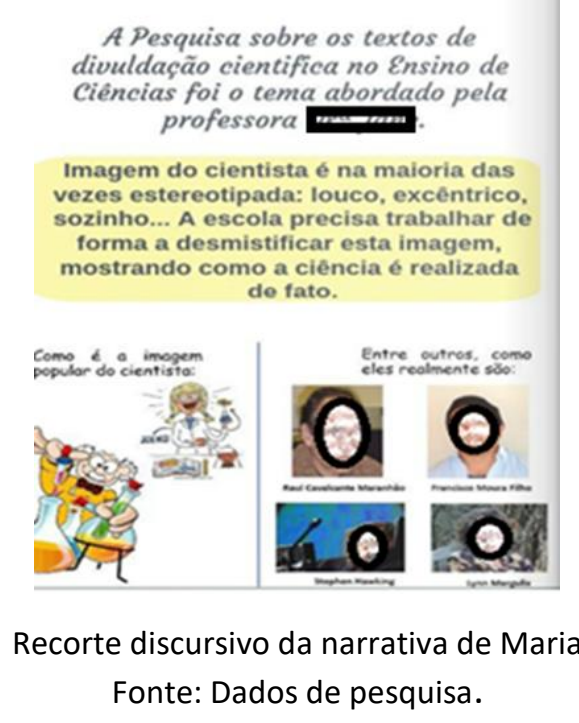

Pela articulação entre texto e imagens, a mestranda contesta o estereótipo do cientista (pesquisador) disseminado nos/pelos discursos estabilizados em contextos enunciativos não especializados como "louco", excêntrico", "sozinho" - adjetivos ilustrados pelas figuras no canto inferior esquerdo. Ao lado, Maria apresenta fotografias de pesquisadores de diferentes áreas fora de seus espaços de trabalho. As fotografias (em vez de desenhos) contribuem para a percepção do cientista como um sujeito comum, como qualquer outro. A relação entre os dois conjuntos de imagens escolhidas pela mestranda ainda contradiz, pelo não-dito, a ideia (mais estabilizada nos discursos tradicionais) de que pesquisa científica só pode ser feita em laboratório.

Os recortes discursivos a seguir, de Manuela e Gisa, também remetem a estereótipos sobre a ciência e corroboram nossa interpretação de que a disciplina provocou movimentos de reflexão e reelaboração discursiva pelas mestrandas quando postas diante do contraste 
entre diferentes formações discursivas acerca da posição-sujeito 'pesquisador' (postas em diálogo durante as aulas).

Por pertencer à área de exatas, havia em mim um certo preconceito em relação à pesquisa qualitativa. E acredito que grande parte das pessoas que vivem no meio acadêmico vivenciam esse preconceito. Apesar de ter optado pela Licenciatura, [...] possuía em mim o sentimento de que não poderia levar tão a sério as pesquisas na área de ensino. [...] Hoje, acredito que fazer ciência é estar em busca do melhor método científico para analisar seu objeto de estudo, seja sua pesquisa qualitativa ou quantitativa. [...] Existe um mar de ciências humanas e eu estou imersa nele. Completamente diferente daquela de antes. (Manuela transcrito)

"Confesso que esse tema ainda me dá arrepios (risos). Eu vim de uma área de pesquisa, na sua grande maioria, quantitativa, em que nos dedicamos a verificar estatisticamente uma hipótese a partir da coleta de dados concretos e quantificáveis, isto é, números. Entrar numa área tão subjetiva como a pesquisa em educação será um desafio a enfrentar. Mas tenho que concordar que o universo investigado é sempre transcendental, muito além do que, em algum momento, você previa ter uma visão final. [...] Na pesquisa qualitativa não 'vale tudo' e nem tudo é aceitável. Uma pesquisa qualitativa deve ser reflexiva e não meramente descritiva". (Gisa)

Considerando, a partir de Orlandi (2012, p. 152), que a discursividade “[...] caracterizase pelo fato de que os sujeitos, em suas posições, e os sentidos, constituem-se pela sua inserção em diferentes formações discursivas", os discursos de Manuela e Gisa trazem com eles todo um contexto discursivo estruturado por formações ideológicas próprias das ciências exatas, do paradigma quantitativo de pesquisa e da visão positivista de ciência. Esse contexto discursivo as constitui em suas posições-sujeito (mestrandas, professoras, pesquisadoras iniciantes). Diante de um contexto discursivo diverso (qualitativo e humanista, no qual a realidade é fluente e contraditória), sentem a desestabilização de seus discursos (e de si mesmas pelo discurso) e buscam formas de harmonizar as ideologias e articulá-las como constitutivas da posição-sujeito 'pesquisador'. 


\section{Considerações}

O processo de formação de pesquisadores em Educação pode ser iniciado já nos primeiros anos da graduação. Entretanto, comumente esse processo inicia-se 'de fato' a partir da pós-graduação stricto sensu, mais especificamente nos cursos de mestrado. É também comum que os ingressantes nesses programas tragam consigo muitas ideias já generalizadas acerca do que seja a pesquisa e o trabalho do pesquisador, além do que seja ocupar essa posição-sujeito. Nesse cenário, este artigo se propôs a analisar discursos de discentes de um mestrado em Educação em Ciências produzidos em narrativas digitais de aprendizagem no contexto de uma disciplina obrigatória ministrada no primeiro semestre de 2018.

Os discursos que emergiram das NDA e analisados neste texto trazem indícios do que os sujeitos consideram como elementos constitutivos da posição-sujeito 'pesquisador', quais sejam:

a) a escrita acadêmico-científica e a autoria como elementos centrais da construção e do trabalho do pesquisador, desconstruindo estabilidades discursivas associadas à rigidez formal deste tipo de escrita bem como sua dissociação da criatividade;

b) o caráter processual da pesquisa e da formação do pesquisador, que se (trans)forma na/pela pesquisa - o que desconstrói sentidos estabilizados que colocam a posição-sujeito 'pesquisador' num lugar de destaque e solidez cognitiva;

c) a percepção, decorrente da desconstrução discursiva apontada no tópico anterior, do obstáculo e da dificuldade como elementos integrantes e essenciais ao processo de investigação científica, além de impulsionadores do trabalho do pesquisador;

d) o reconhecimento do pesquisador como uma posição-sujeito atravessada tanto por razão quanto por emoção - o que se reflete diretamente na prática da pesquisa;

e) a percepção da importância da relação dialética entre pesquisa em Educação e prática pedagógica, num movimento de retroalimentação em que a pesquisa altera a prática e vice-versa;

f) a visão do sujeito-pesquisador enquanto agente de transformação da realidade - o 
que desloca o lugar social do pesquisador movendo-o dos espaços exclusivos da universidade para os espaços menos elitizados e mais comuns da sociedade.

Entendemos que este estudo traz contribuições no sentido de indicar as narrativas digitais de aprendizagem como recursos didáticos possíveis e viáveis na/para a formação de pesquisadores-professores. Além disso, aponta percepções de discentes acerca da pesquisa e do sujeito-pesquisador em Educação: por um lado, construtoras de 'novos' sentidos e, por outro, ainda atravessadas por formações ideológicas associadas fortemente ao senso comum e a sentidos estabilizados que cristalizam concepções positivistas de pesquisa. Finalmente, pretendemos que este estudo abra caminhos para novas investigações que possam lançar luz sobre as percepções discentes sobre o que seja essa posição-sujeito 'pesquisador', abrindo, em decorrência, espaços para discussão dos elementos constitutivos e formativos dos pesquisadores em Educação.

\section{Referências}

ALMEIDA, M. E. B.; VALENTE, J. A. Currículo e Contextos de Aprendizagem: integração entre o formal e o não-formal por meio de tecnologias. Revista e-Curriculum, v. 02, n. 12, p. 11621188, maio/out. 2014. Disponível em:

<http://www.redalyc.org/articulo.oa?id=76632206005 >. Acesso em: 12 fev. 2018.

ALMEIDA, M. E. B.; VALENTE, J. A. Integração currículo e tecnologias e a produção de narrativas digitais. Currículo sem fronteiras, v. 12, n. 3, p. 57-82, set/dez. 2012. Disponível em: <http://www.curriculosemfronteiras.org/vol12iss3articles/almeida-valente.pdf $>$. Acesso em: 02 nov. 2017.

AMORIM, M. O pesquisador e seu outro: Bakhtin nas ciências humanas. São Paulo: Musa Editora, 2004.

BRANDÃO, H. H. N. Introdução à análise do discurso. 3. ed. rev. Campinas: Editora da Unicamp, 2012.

BRUNER, J. A construção narrativa da realidade. Critical Inquiry, v. 18, n. 1, p. 1-21, 1991. Disponível em: $<$ https://www.academia.edu/4598706/BRUNER Jerome. A constru\%C3\%A7\%C3\%A3o narrativa da realidade>. Acesso em: 18 jun. 2018.

CLARKE, R.; ADAM, A. Digital Storytelling in Australia: Academic Perspectives and Reflections. Arts and Humanities in Higher Education, v. 11, n. 1-2, p. 157-176, fev./abr. 2012.

Disponível em: <eric.ed.gov/?id=EJ955497>. Acesso em: 12 maio 2018. 
DICIONÁRIO INFORMAL. Artesania. Disponível em:<https://www.dicionarioinformal.com.br/artesania/>. Acesso em: 24 ago. 2018.

ECKERT-HOFF, B. M. Escritura de si e identidade: o sujeito-professor em formação. Campinas: Mercado de Letras, 2008.

EWALD, A. P.; SOARES, J. C. Identidade e subjetividade numa era de incerteza. Estudo de Psicologia, v. 12, n. 1, p. 23-30, 2007. Disponível em:

<http://www.scielo.br/pdf/epsic/v12n1/a03v12n1.pdf>. Acesso em: 13 jul. 2018.

FOUCAULT, M. O que é um autor? Lisboa: Passagens, 1992.

FREIRE, P. Extensão ou comunicação. 11. ed. Rio de Janeiro: Paz e Terra, 2001.

Kobayashi, M. A Digital Storytelling Project in a Multicultural Education Class for Pre-Service Teachers. Journal of Education for Teaching: International Research and Pedagogy, v. 38, n. 2, p. 215-219, 2012. Disponível em: <eric.ed.gov/?id=EJ993292>. Acesso em: 14 jun. 2018.

MASCIA, M. A. A Subjetividade bilíngue no ciberespaço. In: CORACINI, M. J.; UYENO, E. Y.; MASCIA, M. A. A. (org.). Da letra ao pixel: uma análise discursiva do eu sobre o virtual. Campinas: Mercado de Letras, 2011. p. 369-386.

ORLANDI, E. P. Discurso em Análise: Sujeito, Sentido e Ideologia. Campinas: Pontes Editores, 2012.

ORLANDI, E. P. Análise de discurso: princípios e procedimentos. Campinas: Pontes Editores, 2013.

PROGRAMA DE PÓS-GRADUAÇÃO EM EDUCAÇÃO EM CIÊNCIAS. Componentes Curriculares. Disponível

em: $<$ https://sigaa.unifei.edu.br/sigaa/public/programa/curriculo resumo.jsf?id=349\&lc=pt BR>. Acesso em: 16 jul. 2018.

RIBEIRO, S. P. M. Narrativas digitais na expressão do Eu do aluno do Ensino Superior. 2014. Tese (Doutorado em Multimédia em Educação) - Universidade de Aveiro, Aveiro/PT, 2014.

Disponível em:

$<$ http://porbase.bnportugal.pt/ipac20/ipac.jsp?session=14304B067NL48.812250\&profile=po rbase\&uri=link=3100027 !10110287 !3100024 !3100022\&aspect=basic search\&menu=sea rch\&ri=1\&source $=$ ! bnp\&term $=$ Narrativas + digitais + na+express\%C $3 \% A 30+$ do + Eu+do+aluno+ do+Ensino+Superior\&index=ALTITLE $>$. Acesso em: 14 abr. 2018.

ROBIN, B. R.; McNEIL, S. G. What Educators Should Know about Teaching Digital Storytelling? Digital Education Review, n. 22, p. 37-51, dec. 2012. Disponível em:

<eric.ed.gov/?id=EJ996781>. Acesso em: 12 jun. 2015.

RODRIGUES, A. Narrativas digitais, autoria e currículo na formação de professores mediada pelas tecnologias: uma narrativa-tese. Tese (Doutorado em Educação: Currículo) - Pontifícia Universidade Católica de São Paulo, São Paulo, 2017. Disponível em:<https://sapientia.pucsp.br/handle/handle/20196>. Acesso em: 25 maio 2018. 
RODRIGUES, A.; ALMEIDA, M. E. B. Narrativas digitais na educação e na formação de professores: uma revisão sistemática de literatura. Cadernos de Educação - UFPel, n. 56, p. 107-130, 2017/1. Disponível em: <http://dx.doi.org/10.15210/caduc.v0i56.7945>. Acesso em: 28 maio 2018.

RODRIGUES, A.; ALMEIDA, M. E. B.; VALENTE, J. A. Currículo, narrativas digitais e formação de professores: experiências da pós-graduação à escola. Revista Portuguesa de Educação, v. 30, n. 1, p. 61-83, 2017. Disponível em: <https://doi.org/10.21814/rpe.8871>. Acesso em: 19 jul. 2018.

RODRIGUES, A.; GONÇALVES, L. M. Narrativas digitais na formação de professores: da memória, do registro e do discurso emergem posturas e experiências. Revista Contexto \& Educação, ano 29, n. 94, p. 212-237, set./dez. 2014. Disponível em:

<https://www.revistas.unijui.edu.br/index.php/contextoeducacao/article/view/3979/46>. Acesso em: 19 dez. 2015.

SANTAELLA, L. Linguagens líquidas na era da mobilidade. São Paulo: Paulus, 2007.

Recebido em: 31/08/2018

Aprovado em: 05/11/2018 